\title{
Extending time series of fish biomasses using a simple surplus production-based approach
}

\author{
Margit Eero $^{1, *}$, Brian R. MacKenzie ${ }^{1,2,3}$ \\ ${ }^{1}$ National Institute for Aquatic Resources, Technical University of Denmark, 2920 Charlottenlund, Denmark \\ ${ }^{2}$ Department of Marine Ecology, University of Aarhus, c/o DTU-Aqua, 2920 Charlottenlund, Denmark \\ ${ }^{3}$ Center for Macroecology, Evolution and Climate, Department of Biology, University of Copenhagen, \\ 2100 Copenhagen, Denmark
}

\begin{abstract}
Long time series of fish biomasses are needed in order to understand the changes in marine ecosystems and to set appropriate targets for their management and conservation. Fish biomasses from stock assessments usually cover only the recent 3 to 4 decades, and extending these time series using conventional data-demanding methods will, for many stocks, likely not be possible due to limited historical data. However, catch data are usually available for several decades longer than stock assessments. In the present study, we show that catch data, combined with information on average surplus production rate (SPR), of a stock could be used to derive proxies for pre-assessment biomasses. The sensitivity of biomass estimates to different SPR values was explored using data on 55 stocks from different taxa in the North Atlantic. The time series of biomasses estimated from the assessments could, for most stocks, be reconstructed by applying average stock-specific SPR values for all years, i.e. neglecting inter-annual variability in SPR. The approach of applying the information on SPR from the assessment period to pre-assessment years performed reasonably well in extending the biomass time series by 2 to 6 decades for 5 out of 6 stocks used as test cases. Density dependence and major climate variations were taken into account where such effects on SPR were expected. The main challenge for the approach appeared to be long-term changes in productivity regimes. The apparently consistent average SPR among stocks of a similar species could also facilitate use of the SPR-based approach to derive biomass estimates in contemporary data-poor situations.
\end{abstract}

KEY WORDS: Historical biomass - Surplus production - Productivity regimes - Density dependence $\cdot$ Climate forcing

Resale or republication not permitted without written consent of the publisher

\section{INTRODUCTION}

The need for a long-term perspective in order to understand and manage marine ecosystems is increasingly recognized (Pitcher 2001, Holm 2002, Lotze \& Worm 2009). Information on former abundances of marine animal populations can improve our understanding of long-term changes in the structure and functioning of ecosystems and foodwebs and disentangle the relative impacts of different human and natural drivers (Jackson et al. 2001, Lotze et al. 2006, Eero et al. 2011). Such knowledge can then provide a basis for defining conservation mea- sures and targets for restoration of degraded ecosystems (Jackson \& Hobbs 2009, Smith \& Pike 2009, MacKenzie et al. 2011).

The time series of fish biomasses provided by regular stock assessments are usually relatively short (3 to 4 decades), and most stocks were already intensively exploited far before the modern stock assessments began. An increasing amount of historical evidence related to fish biomasses in pre-assessment periods is becoming available (Ojaveer \& MacKenzie 2007, Lotze \& Worm 2009). However, this information is often difficult to assimilate into complex population dynamics models to estimate quantitative biomasses 
(Alexander et al. 2009). This is partly because historical data on some key fisheries variables (e.g. fishing effort) are often absent or fragmentary and influenced by technological developments (Engelhard 2008), whose effects are difficult to quantify (Ward \& Hindmarsh 2007). Age or size compositions of historical catches are rarely known and fisheriesindependent data from research surveys are only in a few cases available for longer time periods than those covered by modern stock assessments (Cardinale et al. 2009). Snap-shots of historical biomasses have in several cases been estimated (Rosenberg et al. 2005, Poulsen et al. 2007); however, the examples where the annual time series from the assessments have been extended are still relatively few.

Systematic catch data are, for most stocks, available dating back to the 1950s or 1900s, i.e. several decades longer than the biomasses from stock assessments. In the present study, we investigate whether this catch information could be translated into quantitative biomasses using information on the average stock-specific surplus production rate (SPR). The approach uses concepts from classical surplus production modelling, which has previously been used with different modifications to reconstruct historical biomasses (Baker \& Claphan 2004, Rose 2004). The principal difference in our approach is that it does not involve any model fitting, but instead applies empirical knowledge of SPR to pre-assessment years. We first explore the overall level and temporal variability in the SPR of 55 stocks of different species in the North Atlantic, and investigate the sensitivity of biomass estimates to different SPR values. In a second step, we apply the SPR-based approach to backcalculate 2 to 6 decades of pre-assessment biomasses for 6 populations, used as test cases. The results are compared with independent analytical biomass hindcasts available for these stocks.

\section{METHODS}

\section{Data}

We used data on catches, total stock biomasses and fishing mortalities of 55 stocks in the northeast Atlantic, which included 11 cod stocks, 15 stocks of other gadids, 14 flatfish, and 15 stocks of small pelagics. The data were extracted from ICES (International Council for Exploration of the Sea) stock assessment reports (see Tables S1 \& S2 in Supplement 1 at www. int-res.com/articles/m440p191_supp.pdf for the list of stocks). All the stocks included in the analyses were assessed in the reports using analytical agebased assessment methods based on standard virtual population analysis techniques. The assessment data were supplemented by historical hindcasts for Northeast Arctic cod (Hylen 2002), Norwegian springspawning herring (Toresen \& Østvedt 2000), cod and whiting in the North Sea (Pope \& Macer 1996푸), Eastern Baltic cod (Eero et al. 2007) and plaice in the North Sea (Rijnsdorp \& Millner 1996푸). Some calibrations were made to the historical data, as described in Supplement 1.

\section{SPR and changes in productivity over time}

For each stock, we calculated a time series of surplus (net) production (SP), which was defined as:

$$
\mathrm{SP}_{y}=B_{Y+1}-B_{Y}+C_{Y}
$$

where $B_{\mathrm{y}}, \mathrm{SP}_{\mathrm{y}}$ and $C_{\mathrm{y}}$ are the stock biomass, net production and catch in a year $y$, respectively (Walters et al. 2008). Surplus production rate (SPR) in a year $y$ was calculated as SP per unit of biomass:

$$
\mathrm{SPR}_{y}=\frac{B_{y+1}-B_{Y}+C_{Y}}{B_{Y}}
$$

Sequential $t$-test analysis of regime shifts (STARS, Rodionov 2004) was applied on a time series of SPR for each stock, in order to identify significant changes in SPR over time. The settings used in the analyses were a $10 \mathrm{yr}$ data window, a significance value of 0.05 , and a Huber range of 1.0. The shifts detected in the end of the time series, where a potential new regime consisted of less than 5 most recent data points, were neglected. For the purpose of this study, we do not focus on the shifts in productivity as such and their possible drivers, but the productivity changes are only addressed in relation to the approach to back-calculate biomasses based on average SPRs.

\section{Back-calculating biomass using catches and SPR}

Rearranging Eq. (2) allows back-calculating biomass in each year $y$ from annual catches and SPR:

$$
B_{y}=\frac{B_{y+1}+C_{Y}}{1+\operatorname{SPR}_{Y}}
$$

\footnotetext{
1 Data available at Pinnegar J (ed) North Sea Demersal Fish. In: Starkey DJ, Nicholls JH (comp.) Shifting Baselines: INCOFISH WP2 Data Pages. www.hull.ac.uk/incofish
} 
For the purpose of this paper, we hypothesise that replacing the annual $\mathrm{SPR}_{\mathrm{y}}$ values in Eq. (3) with a long-term average does not compromise the biomass dynamics of a stock. To test this hypothesis, we explored the sensitivity of biomass estimates to different SPR values. Altogether, 5 different options for SPR were applied for each stock:

(i) mean SPR value observed during the time period covered by ICES assessment $\left(\mathrm{SPR}_{\mathrm{m}}\right)$

(ii) median of the observed SPR values $\left(\mathrm{SPR}_{\mathrm{med}}\right)$

(iii) first interquartile of the observed SPR values $\left(\mathrm{SPR}_{\mathrm{iq} 1}\right)$

(iv) third interquartile of the observed SPR values $\left(\mathrm{SPR}_{\mathrm{iq3}}\right)$

(v) a random SPR value $\left(\mathrm{SPR}_{\mathrm{rs}}\right)$ was applied for each year, sampled (without replacement) from the values observed for a particular stock. For this option, 1000 replicates of biomass time series were calculated.

The simulated biomass time series $\left(\mathrm{B}_{\text {sim }}\right)$, obtained using annual catches and the different options for SPR values (i to v) were subsequently compared with the original biomasses from the assessments $\left(\mathrm{B}_{\mathrm{obs}}\right)$. This was done as follows:

(1) For each year, calculation of the proportional difference $(\mathrm{dB})$ between $\mathrm{B}_{\mathrm{sim}}$ and $\mathrm{B}_{\text {obs }}$. For years, when $B_{\text {sim }}$ was higher than $B_{\text {obs }}$ the difference was represented by $d B=1-B_{o b s} \times B_{\text {sim }}{ }^{-1}$; for years, when $B_{\text {sim }}$ was lower than $B_{\text {obs }}$ the difference became $\mathrm{dB}=-\left(1-\mathrm{B}_{\text {sim }} \times \mathrm{B}_{\mathrm{obs}}{ }^{-1}\right)$.

(2) Correlation of the time series of $B_{\text {sim }}$ with $B_{\text {obs, }}$ using Spearman's rank-based measure of association.

\section{Application of the SPR-based approach}

For 6 selected stocks, the biomass time series from the ICES assessments were extended for 2 to 6 decades, using the stock-specific $\mathrm{SPR}_{\mathrm{m}}$ observed during the assessment period. The 6 stocks used were cod, whiting and plaice in the North Sea, Northeast Arctic cod, Eastern Baltic cod and Norwegian springspawning herring. These stocks were chosen as test cases because biomass hindcasts, based on similar methods as used in the ICES assessments, were available for these stocks, which allowed validating our SPR-based estimates. Therefore, the time period for which the pre-assessment biomasses were backcalculated was determined by the length of the time series covered by these hindcasts. The purpose of back-calculating pre-assessment biomasses of these stocks is thus not to produce alternative estimates to those available from the literature, but to investigate the performance of the SPR-based approach to esti-
Table 1. Mean values $( \pm \mathrm{SE})$ of surplus production rate $\left(\mathrm{SPR}_{\mathrm{m}}\right)$ applied for back-calculating historical biomasses of the 6 selected stocks. The year ranges show the time period when a particular $\mathrm{SPR}_{\mathrm{m}}$ was observed (period of observation) and the period for which it was applied in the present study (period of application). For cod-arct and her-noss, two biomass back-calculations were perfomed, using $\mathrm{SPR}_{\mathrm{m}}$ values from different time-periods. Cod-arct: North-east Arctic cod; Cod-nsea: North Sea cod; Cod-2532: Eastern Baltic cod; Her-noss: Norwegian spring-spawning herring; Ple-nsea: North Sea plaice; Whg-nsea: North Sea whiting

\begin{tabular}{|lrcc|}
\hline Stock & $\mathrm{SPR}_{\mathrm{m}} \pm \mathrm{SE}$ & $\begin{array}{c}\text { Period of } \\
\text { observation }\end{array}$ & $\begin{array}{c}\text { Period of } \\
\text { application }\end{array}$ \\
\hline Cod-arct & $0.36 \pm 0.04$ & $1946-2007$ & $1900-1945$ \\
& $0.13 \pm 0.15$ & $1946-1949$ & $1900-1945$ \\
Cod-nsea & $0.42 \pm 0.08$ & $1963-2007$ & $1921-1962$ \\
Cod-2532 & $0.39 \pm 0.05$ & $1966-2007$ & $1946-1965$ \\
Her-noss & $0.09 \pm 0.04$ & $1950-2006^{\mathrm{a}}$ & $1907-1949$ \\
& $0.16 \pm 0.05$ & $1988-2006$ & $1907-1929$ \\
& $0.03 \pm 0.05$ & $1950-1969$ & $1930-1949$ \\
Ple-nsea & $0.39 \pm 0.03$ & $1957-2006$ & $1893-1956$ \\
Whg-nsea & $0.17 \pm 0.09$ & $1980-2006$ & $1921-1979$ \\
aExcluding $1970-1987$ & & \\
\hline
\end{tabular}

mate biomasses for time periods where information on production rates is not available. The SPR-based approach applied for the 6 test cases used the information on production rates only from the time periods covered by ICES assessments (Table 1). In this way, our back-calculations for pre-assessment years are independent from the analytical hindcasts and imitate a situation of available knowledge under which the SPR-based approach would practically be applied.

Density dependence and climate forcing can influence fish production rates (Jacobson et al. 2001, Hilborn \& Litzinger 2009). Such effects were expected and incorporated for back-calculating biomasses of Northeast Artic cod and Norwegian spring-spawning herring (see Supplement 2 at www. int-res.com/articles/m440p191_supp.pdf for details). Relatively low SPR values for Northeast Arctic cod observed in the late 1940s (1946 to 1949) were considered possibly related to density dependence and thus more likely to apply for preceding decades than the higher production rates observed during most of the subsequent period of intensive exploitation. SPR of Norwegian spring-spawning herring was expected to be influenced by large-scale climate variations represented by the NAO index. Consequently, 2 different $\mathrm{SPR}_{\mathrm{m}}$ values were applied for the period before the 1950s (Table 1). The results were compared with the biomasses obtained applying the mean SPR observed during the entire assessment period, for the 2 stocks (Table 1). 

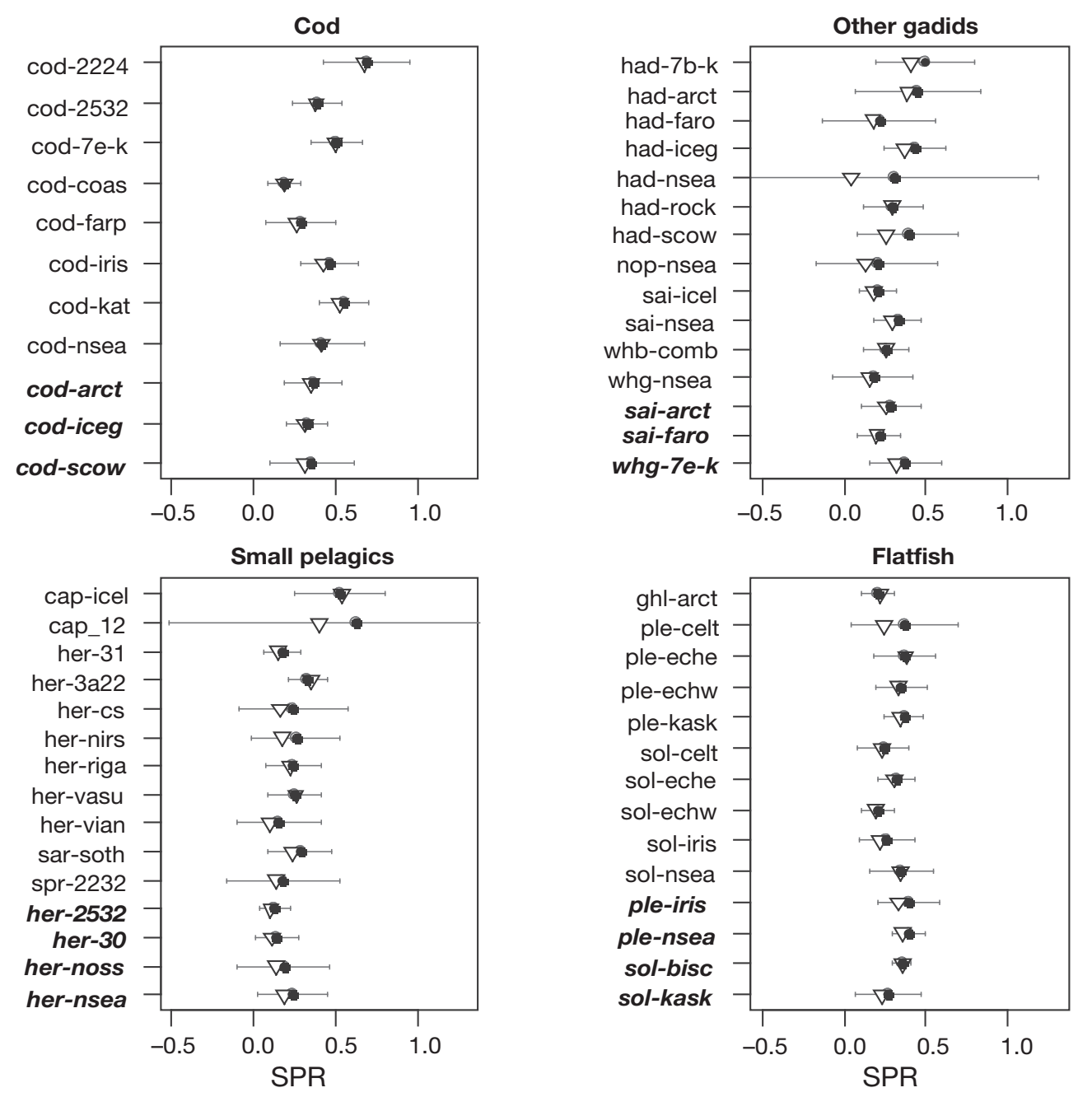

Fig. 1. Mean (filled dots), median (open triangles) and standard deviation (bars) of surplus production rate (SPR) observed during the period covered by ICES stock assessments. See Supplement 1 at www.int-res.com/articles/m440p191_supp.pdf for identification of stocks. For the stocks marked in bold italics, significant changes in SPR during the assessment period were identified

Confidence intervals for pre-assessment biomasses of the 6 stocks represented the effect of standard error of the applied $\mathrm{SPR}_{\mathrm{m}}$. The latter was calculated based on standard deviation of respective SPR data. For each year, an $\mathrm{SPR}_{\mathrm{m}}$ value was randomly selected from the range of confidence intervals for the mean, and 1000 replicates of pre-assessment biomasses were calculated.

\section{SPR values associated with different biomass levels}

SPRs could be expected to vary with stock size, due to density dependent processes (Walters et al. 2008). To identify potential links between the level of biomass and corresponding SPR, we looked at patterns in the observed SPR values associated with different biomass levels using a combined dataset for the 55 stocks included in the analyses. For this purpose, the time series of total biomass and SPR for each stock were standardised relative to the mean value observed in the time-series for a particular stock.

\section{RESULTS}

\section{Variability of SPR values by stocks}

Annual SPRs of most stocks were variable over time and in some cases included values several times higher or lower than the long-term average (Fig. 1). The standard deviation of SPR values is 
shown to be highest for some gadid species (e.g. haddock and Norway pout), and small pelagics (e.g. capelin). The lowest variability in SPR values is generally observed for flatfish stocks. Despite the large inter-annual variability in SPR, average stockspecific SPR (both mean and median) values were often relatively consistent for stocks of a similar species. The mean SPR of herring and sprat stocks were generally the lowest among the analysed species groups with annual values in the range of 100 to $200 \mathrm{~g} \mathrm{~kg}^{-1}$, whereas the mean SPR was mostly 250 to $350 \mathrm{~g} \mathrm{~kg}^{-1}$ for flatfish and 200 to $400 \mathrm{~g} \mathrm{~kg}^{-1}$ for saithe and whiting (Fig. 1). Relatively larger variability in the average SPR is apparent for cod stocks, with values ranging from 200 to $600 \mathrm{~g} \mathrm{~kg}^{-1}$. Mean and median of the observed SPR values were similar for most stock. In cases where these parameters differed, the median of the SPR values was almost always lower than the mean.
Fig. 3). Nevertheless, all correlations between the original biomasses and our back-calculated time series applying either a mean or median of the observed SPR values were positive and significant $(\mathrm{p}<0.05)$.

In contrast, applying randomly sampled SPR values for individual years resulted in generally weaker, and in some cases negative, correlations between the observed and back-calculated biomasses (Fig. 3). Further, annual deviations between the back-calculated and original biomasses became larger, compared to the results applying the mean or median SPR value for all years (Fig. 2). Applying the first or third interquartile of the observed SPR values for all years consistently over- or underestimated the biomass for most years, respectively, in some cases by up to $100 \%$ (e.g. gadids, small pelagics; Fig. 2).

\section{The sensitivity of back-calculated biomasses to different SPR values}

Applying a constant SPR for all years, instead of year-specific values, is expected to over- or under-estimate the biomass for individual years. Our results showed that positive and negative deviations from original biomasses were balanced when applying the mean or median of the observed SPR values for all years. Although the annual deviations were in some cases up to $\pm 50 \%$ (Fig. 2), the overall biomass dynamics was not compromised and the back-calculated biomasses significantly correlated with the original estimates (Fig. 3). The strongest correlations between the observed and back-calculated time series were generally obtained for cod stocks. The correlations were weaker for haddock and for some small pelagic species (capelin, sprat, sardine) (Fig. 3), which are generally characterised by relatively higher inter-annual variability of SPR (Fig. 1). In some cases, weaker correlation between our backcalculations and original biomasses appeared for stocks where significant shifts in the level of SPR had taken place over time (e.g. ple-iris, sol-kask;
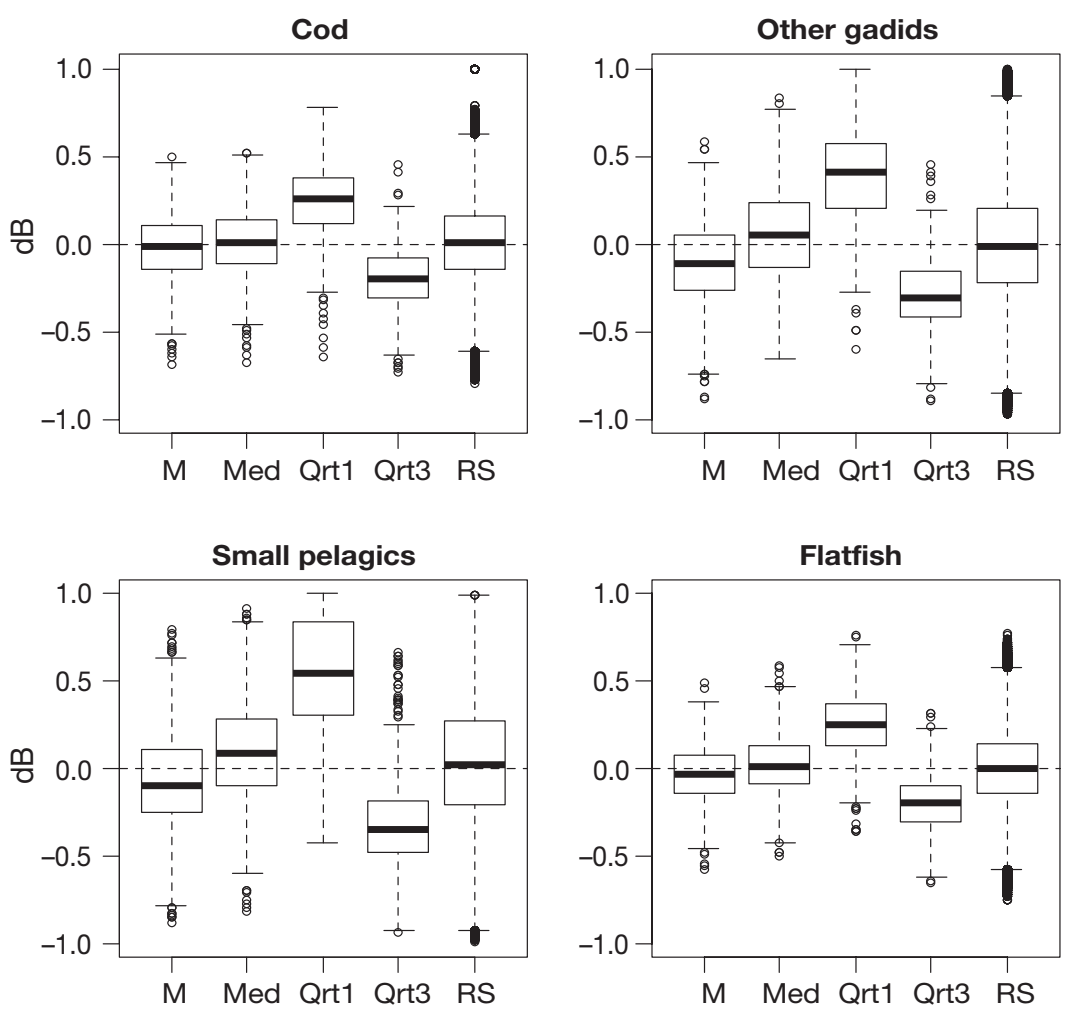

Fig. 2. Variations in annual deviations between simulated and observed biomasses $(\mathrm{dB})$, combined for stocks by species groups. Simulated biomasses are obtained applying mean (M), median (med), first quartile (Qrt1), third quartile (Qrt3), or randomly sampled (RS) surplus production rate values for all years, instead of the observed year-specific values. The positive and negative deviations indicate proportional over- and under-estimation of the biomass, respectively. The boxes of the box and whiskers plots show the difference between first and third quartiles, containing $50 \%$ of the observations. The whiskers represent the lowest value within 1.5 IQR (interquartile range) of the lower quartile and the highest value within 1.5 IQR of the upper quartile. The open circles are outliers 

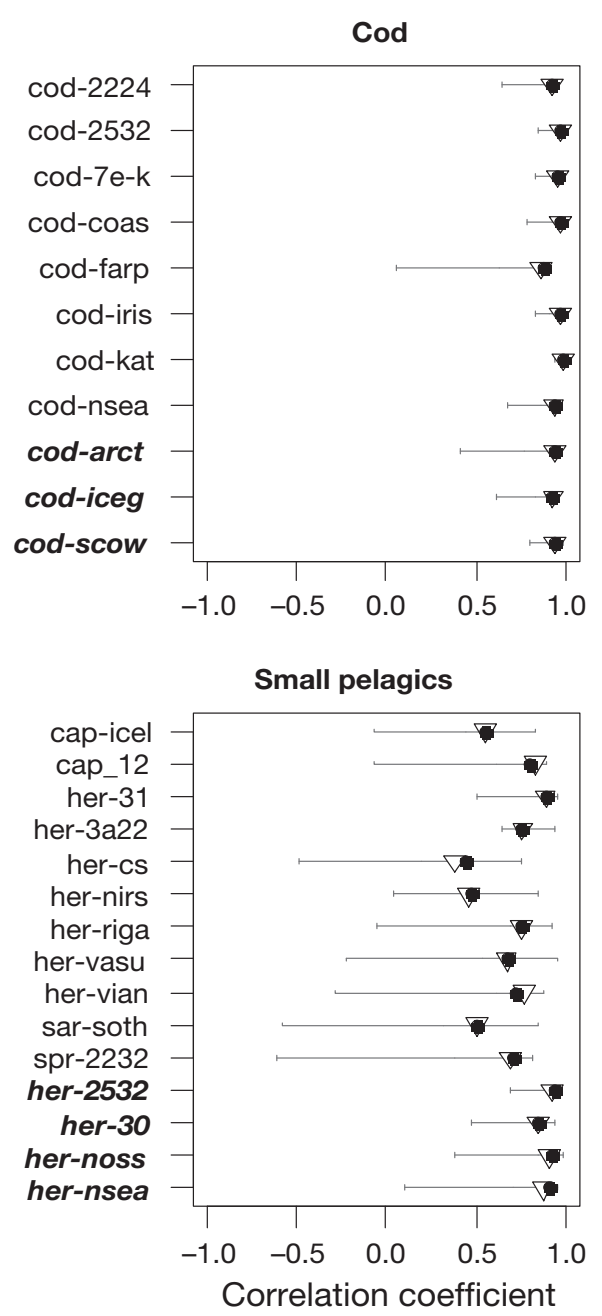
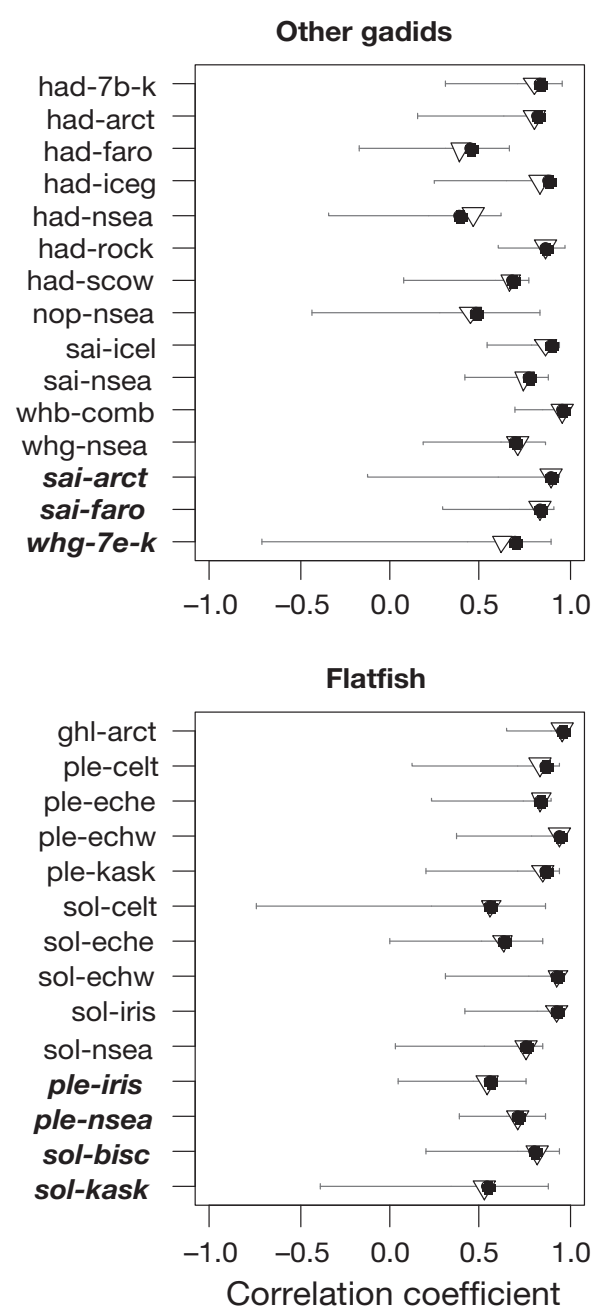

Fig. 3. Correlation coefficients (rho) between the original and back-calculated biomasses, obtained applying mean (filled dots), median (open triangles) or randomly sampled (bars representing the range of rho values obtained from 1000 replicates of biomass estimation) surplus production rate values for all years, instead of year-specific production rates. See Supplement 1 for identification of stocks. For the stocks marked in bold italics, significant changes in SPR during the assessment period were identified

\section{Pre-assessment biomasses estimated using the SPR-based approach}

Applying the $\mathrm{SPR}_{\mathrm{m}}$ observed during the assessment period for 2 to 6 earlier decades produced preassessment biomasses close to the independent analytical estimates for Eastern Baltic cod, North Sea whiting and plaice (Fig. 4). However, for North Sea cod, Northeast Arctic cod and Norwegian springspawning herring, the biomasses back-calculated using the $\mathrm{SPR}_{\mathrm{m}}$ from the entire assessment period were substantially lower compared to the analytical estimates. The correspondence between the analytical hindcasts and our back-calculations was considerably improved when taking into account the expected effects of density dependence and major climate variations on the SPR of Northeast Arctic cod and Norwegian spring-spawning herring, respectively (Fig. 4).

A discrepancy between the analytical hindcast and our back-calculation remained for North Sea cod (Fig. 4). Applying mean SPR observed in the entire assessment period to the years from the early 1960s back to the 1920 s underestimated the pre-assessment biomass by approximately $50 \%$ (Fig. 4). According to the historical estimates, the SPR of North Sea cod significantly increased in the early 1960s, just before the beginning of the ICES assessment (Fig. 5). Interestingly, the increase in SPR of North Sea cod in the early 1960s coincided with increased productivity of 2 other major cod stocks in the North Atlantic-Northeast Arctic and Icelandic cod-for 

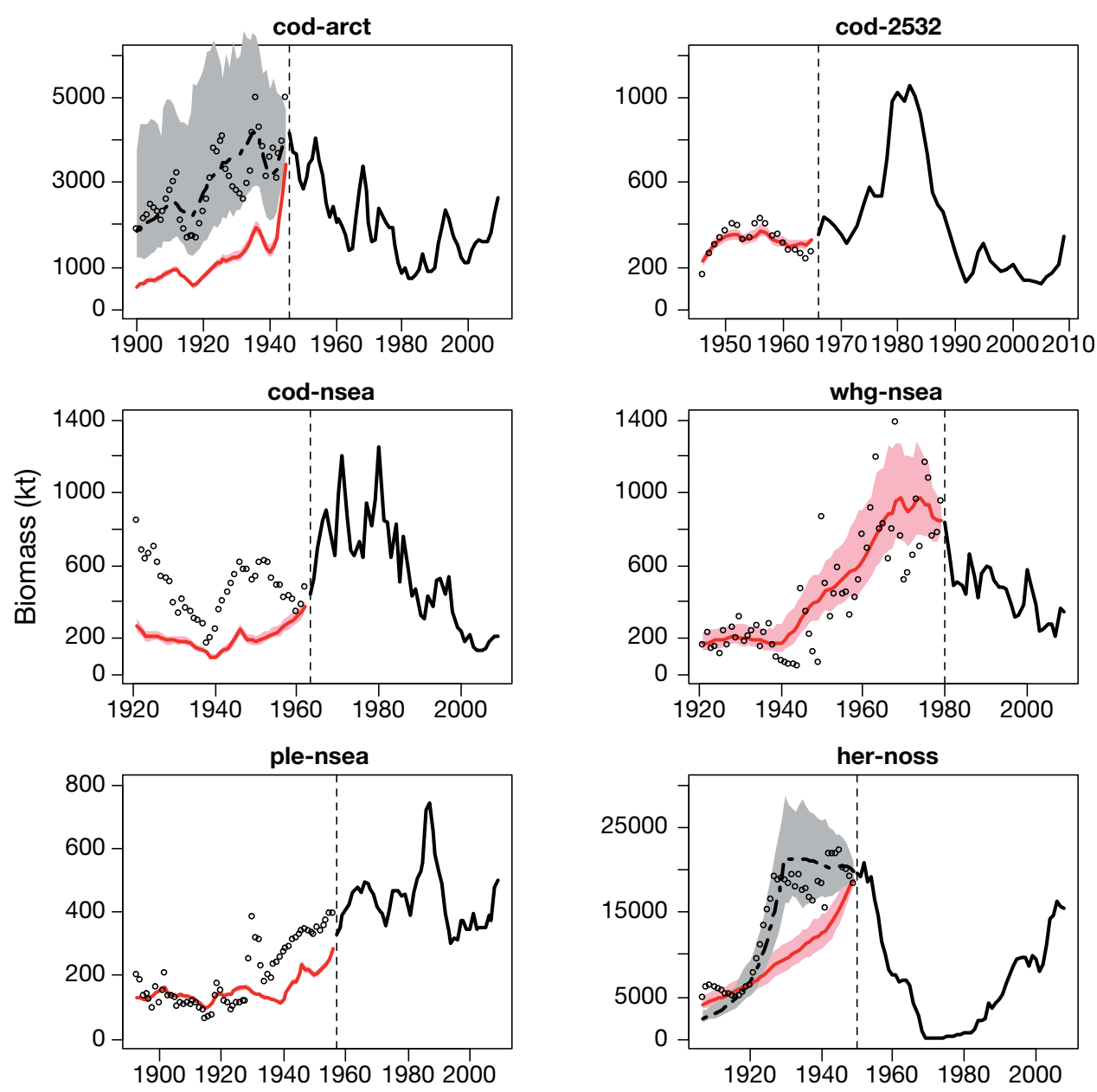

Fig. 4. Biomasses of Northeast Arctic cod (cod-arct), North Sea cod, whiting and plaice (cod-nsea, why-nsea and ple-nsea, respectively), Eastern Baltic cod (cod-2532) and Norwegian spring-spawning herring (her-noss). Biomasses for preassessment years are back-calculated based on mean surplus production rates $\left(\mathrm{SPR}_{\mathrm{m}}\right)$ observed during the assessment period (solid red lines). For cod-arct and her-noss, alternative biomass estimates taking into account expected effects of density dependence and climate variability, respectively, are presented (black broken lines). The confidence intervals (shaded areas) represent the effect of standard error of the $\mathrm{SPR}_{\mathrm{m}}$ value applied in the calculations. The back-calculated biomasses are shown in comparison with hindcasts using virtual population analysis methods (dots). Vertical dashed lines mark the beginning of biomass time series from regular ICES assessments (solid black lines)

which longer assessment histories from ICES are available (Fig. 5).

\section{SPR values corresponding to different biomass levels}

Within the range of values observed in the available time series, the above-average biomasses were mostly associated with below-average SPR values. However, similar low production rates also occurred at relatively low biomasses. At below-average biomass levels, the relatively higher and lower SPR values compared to the mean were equally represented (Fig. 6).

\section{DISCUSSION}

\section{Considerations for assumptions on pre-assessment production rates}

The approach of back-calculating fish biomasses based on annual catches and SPRs relies on the assumption of the level of productivity in preassessment years. Assuming that the average SPR in pre-assessment years was similar to the assessment period, the biomass time series can easily be extended by applying the mean or median of the SPR values observed. In our examples, the SPR of North Sea plaice and whiting from the assessment period could successfully be back-extrapolated for 60 more 

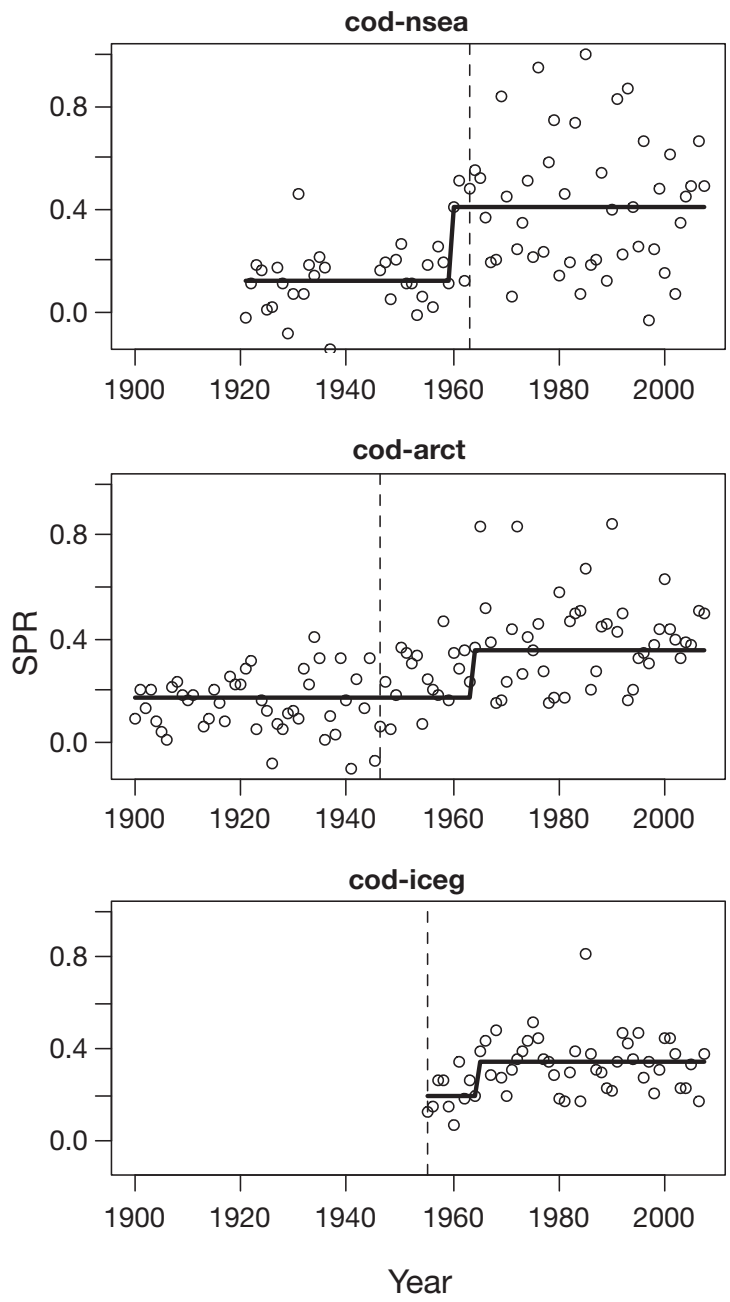

Fig. 5. Time series of surplus production rate (SPR) for North Sea cod (cod-nsea), Northeast Arctic cod (cod-arct) and Icelandic cod (cod-iceg) (dots). Solid lines depict the average SPR by regimes, identified by regime shift analyses (STARS). Vertical dashed lines mark the beginning of the time period covered by ICES assessments; earlier data are from the analytical hindcasts available in the literature (Pope \& Macer 1996, Hylen 2002)

years, which is longer than the ICES assessment history for these stocks (Fig. 4). The approach appeared to be robust to inter-annual fluctuations and shortterm changes in productivity (Figs. $2 \& 3$ ).

Applying the mean or median SPR would in most cases likely lead to a similar result as the values for the 2 parameters have been similar for most stocks (Fig. 1). However, for some stocks (e.g. haddock, capelin), very high SPR values have occasionally been observed, resulting in a higher mean SPR for these stocks compared to the median (Fig. 1). In such cases, applying the mean SPR would under-estimate the annual biomass more often than over-estimate it,

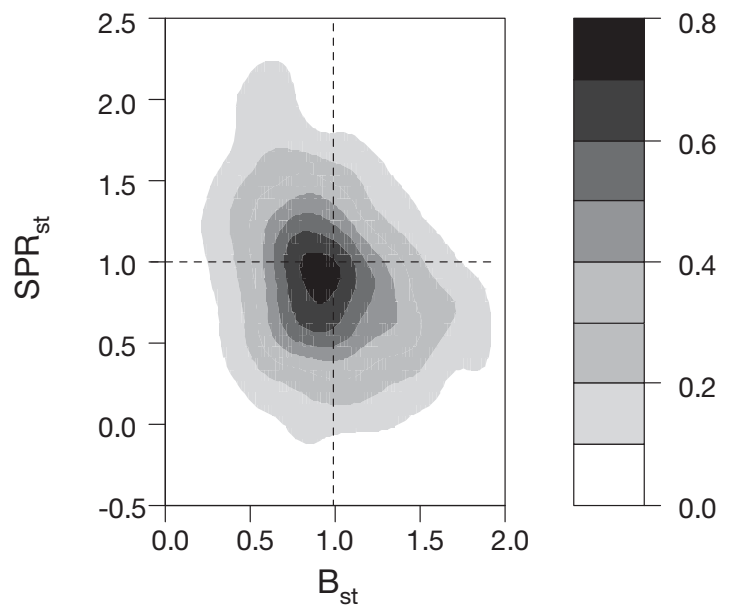

Fig. 6. Annual standardized surplus production rate $\left(\mathrm{SPR}_{\mathrm{st}}\right)$ corresponding to the relative biomass $\left(\mathrm{B}_{\mathrm{st}}\right)$ in the same year, combined for all stocks included in the analyses. The values above and below 1 represent proportionally higher or lower $\mathrm{B}$ or SPR values in a given year compared to the long-term mean, respectively. Density of the observations is estimated using a 2-dimensional kernel density function

whereas applying the median SPR could produce more balanced results (Fig. 2).

The main challenge for the SPR-based approach appeared to be longer time periods with different mean levels of productivity (Mohn \& Chouinard 2007). Applying consistently too high or too low SPR values for individual years can result in a substantial under- or overestimation of the overall level of biomass (Figs. $2 \& 4$ ). SPR is considered to vary either with stock size due to density dependence (Walters et al. 2008), or due to changes in environmental or other ecosystem-related factors (e.g. Jacobson et al. 2001).

\section{Density dependence}

According to the theory of density dependence, SPRs are expected to follow a dome-shaped pattern, where the productivity of unexploited biomass is close to zero and the highest productivity corresponds to an intermediate biomass level (Schaefer 1954). Logistic population growth models assume the rate of production to increase continuously as the stock abundance declines (Hilborn \& Litzinger 2009). Alternative hypotheses suggests the opposite, i.e. the SPR declines at a low biomass (Hutchings 2000, Hutchings \& Reynolds 2004). In practice, the dependence of SP on stock size is difficult to detect, as factors other than stock size impact on recruitment and other parameters of SP (Walters et al. 2008). 
The stock biomasses and their exploitation rates varied many-fold during the period of available data (Fig. 6, Supplement 3 at www.int-res.com/ articles/m440p191_supp.pdf). The relatively higher biomasses were generally associated with belowaverage SPR values, which could be related to density dependence. However, similar low SPR values were also observed at low biomasses (Fig. 6). Moreover, the observed SPR values did not show any association with concurrent exploitation rates (Supplement 3). We conclude that for the stocks exploited at least at a moderate level, and when the biomass is not far outside the observed range, density dependence is likely not a major concern for backcalculating biomasses based on SPR.

However, density dependence may become a concern for making assumptions on historical production rates when the stock size reaches higher levels than those observed in the assessment period and when the exploitation rate is low. In such a situation, and when a relationship between the stock size and a corresponding SPR cannot be established, applying the lowest SPR level observed for a particular stock may be a reasonable option. This approach was followed in the example for Northeast Arctic cod, where applying the low average SPR observed in the 1940s generated a pre-assessment biomass trajectory more similar to the available analytical hindcast, compared to the back-calculation that applied the average SPR from the entire assessment period (1946-2007). However, this approach may not be applicable for earlier time periods with low exploitation when the structure and properties of fish communities were different, including higher biomasses of top predators (Rosenberg et al. 2005, Lotze \& Worm 2009). Competition for both prey and space may have resulted in different production rates of individual populations than those observed in the 20th century, in the period of intensified exploitation. Therefore, when the SPRbased approach is used for estimating fish biomasses further back than the 20th century, the results should be treated with caution.

\section{Environmental and ecological impacts}

Environmental conditions can influence productivity of fish stocks either directly, through physiological processes, or indirectly, through ecosystem processes such as food availability and predation (Stenseth et al. 2002, Brander 2007, Möllmann et al. 2009). Climate effects are generally considered to most dramatically influence small pelagic species (Alheit \&
Hagen 1997, MacKenzie \& Köster 2004, Cahuin et al. 2009). For stocks where links between stock productivity and climate variables can be established, climate effects could be incorporated in backcalculating historical biomasses, as data on climate variables are usually available for longer time periods than stock assessments. This is demonstrated in the example of Norwegian spring-spawning herring, where applying different $\mathrm{SPR}_{\mathrm{m}}$ values for different periods, according to major changes in climate forcing, improved the correspondence between the analytical estimates and our back-calculations compared to the analyses applying a constant production rate for all years (Fig. 4).

Accounting for changes in production rates is challenging in situations where the mechanisms causing changes in productivity regimes are not fully understood. In our example, the apparently simultaneous increase in productivity of the 3 largest cod stocks in the North Atlantic, i.e. Northeast Arctic, Icelandic and North Sea cod, in the 1960s (Fig. 5) is particularly interesting because the 3 stocks inhabit widely different thermal ranges, whereas temperature is considered to have opposite effects on cod stocks distributed in northerly and southerly areas (Planque \& Fredou 1999, Mantzouni \& MacKenzie 2010). Synchronies and asynchronies of population responses within and between oceanic regions and between functional groups are likely to occur (Link et al. 2009, Megrey et al. 2009). The SPR-based approach for back-calculating biomasses would greatly benefit from an improved understanding of these mechanisms and how a change in productivity of one stock could relate to neighbouring populations. This understanding could facilitate using long-term data, which are available for some stocks, to improve the assumptions on historical production rates for related populations. For example, this approach could potentially have enabled us to account for a lower productivity of North Sea cod before the early 1960s (Fig. 4), when longer assessment history available for Northeast Arctic and Icelandic cod indicated lower productivity for these stocks (Fig. 5).

\section{Practical applications for the SPR-based approach}

The SPR-based approach for back-calculating fish biomasses is considered to be best applicable for periods with moderate to high exploitation rates. Within the range of exploitation rates represented in the available data, the accuracy of the backcalculated biomasses did not appear to be associated 
with concurrent levels of fishing mortality (Supplement 3). However, it could be expected that in situations of very low fishing, when the stock dynamics are largely driven by biological productivity, the uncertainties in assumed production rates become more influential for the resulting biomass estimates. The time scale for which the SPR-based approach could be applied is thus stock-specific and depends on, amongst other factors, fisheries developments. The fisheries in North Atlantic were generally developed far before the modern stock assessments began (Holm \& Starkey 1998), and systematic catch data is available for most stocks extending back to at least the 1950 s or the early 1900s. Given that most stock assessment time series begin only in the 1970s or later (Table S2 in Supplement 1), the SPR-based approach could facilitate extending the biomasses of many stocks for several more decades than currently available from the assessments. When applied for different species, the accuracy of the back-calculated biomasses should generally be expected to be relatively lower for species with high inter-annual variability in production rates (Fig. S4 in Supplement 4 at www.int-res.com/articles/m440p191_supp.pdf).

Making assumptions on SPR may be challenging in situations where large changes in ecosystem structure or productivity have taken place, for example due to eutrophication, or removal of large marine predators (Lotze \& Worm 2009, Eero et al. 2011). However, many populations of top predators already declined before the 20th century (Lotze \& Worm 2009), i.e. before the time period that the SPR approach is intended to be mainly applied to. Further, and perhaps unexpectedly, the well-documented regime shifts in the late 1980s in the North Sea (Beaugrand et al. 2003, Beaugrand 2004) and in the Baltic Sea (Köster et al. 2003, Möllmann et al. 2009), which, amongst other factors, involved declines of recruitment of gadoids in both areas, do not appear to have caused a significant change in the SPR of these species (Table S2 in Supplement 1). This could be due to processes impacting different components of SP which could counteract each other (Lorenzen \& Engberg 2002) and lead to a stable SPR. The productivity rate may thus, in some cases, be more robust to ecosystem changes than its individual components, which is beneficial for the SPR-based approach. The back-calculated biomasses could be evaluated for potential bias using any supporting information, such as qualitative or anecdotal information from the fisheries, or some fragmentary data on changes in population abundance. This type of information usually forms the largest body of available historical evi- dence (Starkey et al. 2007, Fortibuoni et al. 2010), and could be very valuable for validating the time series of biomass dynamics from methods such as the SPR-based approach.

The SPR-based approach is considered to be particularly useful in relation to multi-species and ecosystem analyses. The length of available biomass time series usually differs widely between populations inhabiting a given ecosystem. This is a common problem for multi-species and food-web modelling (Hjermann et al. 2007) and the timescale considered in these models is usually determined by the shortest time series. The SPR-based approach could facilitate obtaining proxies for longer-term biomass developments for stocks with short assessment information, and consequently allow making use of the longerterm information which may be available for some species, to evaluate different hypotheses related to ecosystems and their drivers. In this way, our approach can complement the results from other methods used for long-term biomass estimates and ecosystem analyses, such as those from Ecopath models (e.g. Christensen et al. 2003), which are based on a different set of assumptions (e.g. diet composition and predator-prey functional responses).

In addition to extending the biomass time series for stocks for which assessments are available, the SPRbased approach could also be useful in contemporary data-poor situations, where routine stock assessments are not performed. Average production rates appear in some cases to be relatively consistent for stocks of a similar species (Fig. 1). Thus, if a starting value for a biomass for some recent year can be estimated, for example from survey data, and a time series of catch data is available, the knowledge of average production rates of related populations could facilitate deriving proxies for biomass dynamics.

In summary, we believe that when applied with a suitable caution, the SPR-based approach can contribute to developing a longer term perspective in marine ecology and management. It could provide proxies for biomasses developments for several more decades than currently available from the assessments, for stock for which longer time series will otherwise likely never be available due to insufficient data for conventional methods. The simple approximation of biomass dynamics based on production rates could support the investigations of longer-term developments in fish communities and foodwebs and contribute to providing new insights into the impacts of various natural and human drivers. 
Acknowledgements. This study was supported by the History of Marine Animal Populations (HMAP) project in the Census of Marine Life program, the Danish Network for Fisheries and Aquaculture Research (FISHNET) and the Danish National Research Foundation project Center for Macroecology, Evolution and Climate (CMEC). We thank J. Pope for providing original data from his earlier works, and 3 anonymous reviewers for helpful comments and suggestions.

\section{LITERATURE CITED}

Alexander KE, Leavenworth WB, Cournane J, Cooper AB and others (2009) Gulf of Maine cod in 1861: historical analysis of fishery logbooks, with ecosystem implications. Fish Fish 10:428-449

> Alheit J, Hagen E (1997) Long-term climate forcing of European herring and sardine populations. Fish Oceanogr 6: 130-139

Baker CS, Clapham PJ (2004) Modelling the past and future of whales and whaling. Trends Ecol Evol 19:365-371

> Beaugrand G (2004) The North Sea regime shift: evidence, causes, mechanisms and consequences. Prog Oceanogr 60:245-262

Beaugrand G, Brander KM, Lindley JA, Souissi S, Reid PC (2003) Plankton effect on cod recruitment in the North Sea. Nature 426:661-664

Brander KM (2007) Global fish production and climate change. Proc Natl Acad Sci USA 104:19709-19714

> Cahuin SM, Cubillos LA, Niquen M, Escribano R (2009) Climatic regimes and the recruitment rate of anchoveta, Engraulis ringens, off Peru. Estuar Coast Shelf Sci 84: 591-597

> Cardinale M, Linder M, Bartolino V, Maiorano L, Casini M (2009) Conservation value of historical data: reconstructing stock dynamics of turbot during the last century in the Kattegat-Skagerrak. Mar Ecol Prog Ser 386:197-206

Christensen V, Guenette S, Heymans JJ, Walters CJ, Watson R (2003) Hundred-year decline of North Atlantic predatory fishes. Fish Fish 4:1-24

Eero M, Köster FW, Plikshs M, Thurow F (2007) Eastern Baltic cod (Gadus morhua callarias) stock dynamics: Extending the analytical assessment back to the mid1940s. ICES J Mar Sci 64:1257-1271

> Eero M, MacKenzie BR, Köster FW, Gislason H (2011) Multidecadal responses of a cod (Gadus morhua) population to human-induced trophic changes, exploitation and climate variability. Ecol Appl 21:214-226

Engelhard GH (2008) One hundred and twenty years of change in fishing power of English North Sea trawlers. In: Payne A, Cotter J, Potter J (eds) Advances in Fisheries Science. 50 years on from Beverton and Holt. Blackwell Publishing, Oxford, p 1-25

Fortibuoni T, Libralato S, Raicevich S, Giovanardi O, Solidaro C (2010) Coding early naturalists' accounts into long-term fish community changes in the Adriatic Sea (1800-2000). PLoS ONE 5:e15502

Hilborn R, Litzinger E (2009) Causes of decline and potential for recovery of Atlantic cod populations. Open Fish Sci J 2:32-38

Hjermann DØ, Bogstad B, Eikeset AM, Ottersen G, Gjøsæter H, Stenseth NC (2007) Food web dynamics affect Northeast Arctic cod recruitment. Proc Biol Sci 274:661-669
Holm P (2002) History of marine animal populations: a global research program of the census of marine life. Oceanol Acta 25:207-211

Holm P, Starkey DJ (eds) (1998) North Atlantic Fisheries. Markets and modernisation. Studia Atlantica, 2, Centre for Maritime and Regional History, Esbjerg

> Hutchings JA (2000) Collapse and recovery of marine fishes. Nature 406:882-885

> Hutchings JA, Reynolds JD (2004) Marine fish population collapses: consequences for recovery and extinction risk. BioScience 54:297-309

Hylen A (2002) Fluctuations in abundance of Northeast Arctic cod during the 20th century. ICES Mar Sci Symp 215:543-550

Jackson ST, Hobbs RJ (2009) Ecological restoration in the light of ecological history. Science 325:567-569

> Jackson JBC, Kirby MX, Berger WH, Bjorndal KA and others (2001) Historical overfishing and the recent collapse of coastal ecosystems. Science 293:629-637

> Jacobson LD, De Oliveira JAA, Barange M, Cisneros-Mata MA and others (2001) Surplus production, variability, and climate change in the great sardine and anchovy fisheries. Can J Fish Aquat Sci 58:1891-1903

Köster FW, Möllmann C, Neuenfeldt S, Vinther M and others (2003) Fish stock development in the central Baltic Sea (1976-2000) in relation to variability in the physical environment. ICES Mar Sci Symp 219:294-306

> Link JS, Stockhausen WT, Skaret G, Overholtz W and others (2009) A comparison of biological trends from four marine ecosystems: synchronies, differences, and commonalities. Prog Oceanogr 81:29-46

Lorenzen K, Engberg K (2002) Density-dependent growth as a key mechanism in the regulation of fish populations: evidence from among-population comparisons. Proc Biol Sci 269:49-54

Lotze HK, Worm B (2009) Historical baselines for large marine animals. Trends Ecol Evol 24:254-262

> Lotze HK, Lenihan HS, Bourque BJ, Bradbury RH and others (2006) Depletion, degradation, and recovery potential of estuaries and coastal seas. Science 312:1806-1809

> MacKenzie BR, Köster FW (2004) Fish production and climate: sprat in the Baltic Sea. Ecology 85:784-794

> MacKenzie BR, Ojaveer H, Eero M (2011) Historical ecology provides new insights for ecosystem management: eastern Baltic cod case study. Mar Policy 35: $266-270$

Mantzouni I, MacKenzie BR (2010) Productivity responses of a widespread marine piscivore, Gadus morhua, to oceanic thermal extremes and trends. Proc Biol Sci 277: 1867-1874

> Megrey BA, Hare JA, Stockhausen WT, Dommasnes A and others (2009) A cross-ecosystem comparison of spatial and temporal patterns of covariation in the recruitment of functionally analogous fish stocks. Prog Oceanogr 81: 63-92

> Mohn RK, Chouinard GA (2007) Harvest control rules for stocks displaying dynamic production regimes. ICES J Mar Sci 64:693-697

Möllmann C, Diekmann R, Müller-Karulis B, Kornilovs G, Plikshs M, Axe P (2009) Reorganization of a large marine ecosystem due to atmospheric and anthropogenic pressure: a discontinuous regime shift in the central Baltic Sea. Glob Change Biol 15:1377-1393

Ojaveer H, MacKenzie BR (2007) Historical development of fisheries in northern Europe-reconstructing chronology 
of interactions between nature and man. Fish Res 87: 102-105

Pitcher TJ (2001) Fisheries managed to rebuild ecosystems? Reconstructing the past to salvage the future. Ecol Appl 11:601-617

Planque B, Fredou T (1999) Temperature and recruitment of Atlantic cod (Gadus morhua). Can J Fish Aquat Sci 56: 2069-2077

Pope JG, Macer CT (1996) An evaluation of the stock structure of North Sea cod, haddock, and whiting since 1920, together with a consideration of the impacts of fisheries and predation effects on their biomass and recruitment. ICES J Mar Sci 53:1157-1169

Poulsen RT, Cooper AB, Holm P, MacKenzie BR (2007) An abundance estimate of ling (Molva molva) and cod (Gadus morhua) in the Skagerrak and the northeastern North Sea, 1872. Fish Res 87:181-196

Rijnsdorp AD, Millner RS (1996) Trends in population dynamics and exploitation of North Sea plaice (Pleuronectes platessa L.) since the late 1800s. ICES J Mar Sci 53:1170-1184

Rodionov SN (2004) A sequential algorithm for testing climate regime shifts. Geophys Res Lett 31, L09204, doi:10.1029/2004GL019448

Rose GA (2004) Reconciling overfishing and climate change with stock dynamics of Atlantic cod (Gadus morhua) over 500 years. Can J Fish Aquat Sci 61:1553-1557

Editorial responsibility: Konstantinos Stergiou, Thessaloniki, Greece
Rosenberg AA, Bolster WJ, Alexander KE, Leavenworth WB, Cooper AB, McKenzie MG (2005) The history of ocean resources: modeling cod biomass using historical records. Front Ecol Environ 3:78-84

Schaefer MB (1954) Some aspects of the dynamics of populations important to the management of commercial marine fisheries. Inter-Am Trop Tuna Comm Bull 1:27-56

Smith TD, Pike DG (2009) The enigmatic whale: the North Atlantic humpback. NAMMCO Scientific Publications 7: $61-78$

Starkey DJ, Holm P, Barnard M (eds) (2007) Oceans Past. Management insights from the History of Marine Aminal Populations. Earthscan Research Editions, London

Stenseth NC, Mysterud A, Ottersen G, Hurrell JW, Chan KS, Lima M (2002) Ecological effects of climate fluctuations. Science 297:1292-1296

Toresen R, Østvedt OJ (2000) Variation in abundance of Norwegian spring-spawning herring (Clupea harengus, Clupeidae) throughout the 20th century and the influence of climatic fluctuations. Fish Fish 1:231-256

Walters CJ, Hilborn R, Christensen V (2008) Surplus production dynamics in declining and recovering fish populations. Can J Fish Aquat Sci 65:2536-2551

Ward P, Hindmarsh S (2007) An overview of historical changes in the fishing gear and practices of pelagic longliners, with particular reference to Japan's Pacific fleet. Rev Fish Biol Fish 17:501-516

Submitted: December 20, 2010; Accepted: August 12, 2011 Proofs received from author(s): October 14, 2011 